\title{
Advice on Construction of Literature Resources
}

\author{
Zhuqun $\mathrm{Li}^{1, \mathrm{a}}$ \\ ${ }^{1} \mathrm{Ji}$ Lin Business and Technology College,Chang Chun, Ji Lin,130507, China \\ alizhuqun@jlbtc.edu.cn.
}

Keywords: Library; Literature Resource; Grey Literature; Subject Navigation; Database .

\begin{abstract}
In the library of the new approved normal four-year university, how to deal with the change of direction of running a college, of function and the structure of the subject construction, etc. is very important. The writer surveyed some libraries in the university famous in economics major and looked into the readers of students and teachers in about 4 school years. Information resource of the library can be improved in the amount and the quality, and the carriers can be new carriers and the traditional paper. The librarians should set up database of relevant majors and subject navigation in the new web page. The librarians may collect more grey literature resources like the experiment reports, etc. and use CASHL more times for researchers. The information resource is more necessary to the readers for research and the construction of it is more important to the librarians.
\end{abstract}

\section{Introduction}

After changing the junior college into college, the level of running a school has been up to the college. In the subject structure the many discipline should be developed gradually and comprehensively from single discipline with the promotion of the level of culture and the demand of knowledge substantially, so as to the new situation of the college can be adapted, and the service can be supply for the teaching and the scientific research by the college library.

\section{The Construction of the Amount of the Literature Resource}

It has not the conclusion that the amount of books of a library of the approved college can meet the needs of the teaching and the scientific study or not and the standard of a qualified literature support system. But the relative files by the Ministry of Education can be referred to. According to the Rules of Ordinary High School Library[1], the amount of books per student can be up to 100, and 4 books should be added. Now it has been more than 860 thousand books in our college library, and up to 70 books per student, so it has a large distance referring to the level of college. Because of the limit of the funds and the inflation of the price of books only one books can be added per student every year. The major problem is the shortage of the funds. In a long term the funds for purchasing the books was short, which caused the speed of increasing of new books slowly and slowly, which led to the amount of relative literature of newly built was very few and very short and can not meet the need of teachers and students in those subject. This problem can be taken seriously by the new built college leaders, then increase the input on the literature resource construction and implement the fund for purchasing books strictly every year. With these measures the system and integrity of the collection of books can be protected, the quality of literature resource of books in the library can also be promoted, and the enthusiasm and initiative of using the college libraries by the readers can be improved. The index of qualification of the fund referring to the level of evaluation of the undergraduate teaching is that the rate of fund for buying books every year in the college should up to $3 \%$. And in this measure part of the demand of some literature can be reached which can not be collected limited by the shortage of the funds. On the other hand the electronic publications and the virtual collections is a supplement for the collection of the library which has high quality and inexpensive. In a optical disc of $12 \mathrm{~cm}$ a MPEG film of more than 1 hour or music of 74 minutes or data of $680 \mathrm{MB}$ can be stored. An optical disc of 3.5 inches can stored all of the contents of PEOPLE DAILY of 10 years. Now the Chinese Science and Technology Periodical Database, the China Academic Periodical, SCI database and the Super Star Library all have the carrier of optical disc. Virtual collection of the books is an important side in 
the construction of the literature resource. With the rapid development of the internet technology, the literature resource in the network has gained the favor of the libraries as a new carrier for its large amount of storage, the quick speed in storing and reading, convenient retrieval performance and the low cost in transmission, which supplements the collection resources in the high school libraries. The virtual collection is the network database or the network information resources. In other words the libraries connect the network to reach the center of transmission of varied commercial electronic literature, the center of the on line information retrieval system and the center of the electronic magazines. The information outside does not belong to the library of college, but because the library connect the net and retrieve the valuable information and offer the service to the readers, these information resources has been a part of the ones of the libraries, so called the virtual collection. Now the CNKI (China National Knowledge Infrastructure), the Wan Fang Database, electronic annual and the XDF (Xin Dong Fang) database all adapted by our library and were regarded with great favor and approval by the teachers and students in our college, so the rate of using them is very high.

\section{The Construction of Quality of the Literature Resources}

First, the characteristic collection books should be built in the libraries of the colleges. The Rules of Ordinary High School Library[2] regulates that the university libraries make the construction plan of literature information resource and form the collection books systems with its own characteristics according to the developing objective of the university and the demand of teaching and science study, the basis of the collection books and the overall arrangement of the system of literature resource distribution. It is the developing trend in the situation of network to construct the characteristic collection books. A mere repetition in literature resource owned by the libraries of college has no meaning. If the literature resources has their own features in different libraries, the network will be the gold mine of complete and integrated literature resources. So it is the necessary situation for the survival and development in the environment of network. The writer deem that the university libraries should do in several aspects of the work. First, to know the situation of key subjects or new added courses, to choose the key subjects, characteristic majors, excellent courses and key scientific topics, to rich the collections around these keys, to pay more attentions to the timeliness and pertinence of construction of the collections of literature resources. Second, to know the readers' advice and suggestion to construction of collections of literature resources, especially the important readers, such as the major leaders of the college, the academic leaders, which can foresee and direct the developing direction of the college or the subject construction, to avoid the blindness in buying the books and ensure that the collections of books are in front of the subject construction. Thirdly, to take seriously the collecting the publications or academic literature by the teachers or students, to form the one and only characteristic collections of the college libraries. The scientific plan of collections of books should be met the need of the undergraduate teaching and scientific study in several aspects such as the level of the collections of the books, the subject structure, the hierarchical structure, the language structure and the type structure, the changing situation should be known.

\section{Take Seriously both New Carriers and Traditional Ones}

To achieve the research of all kinds of literature resources, librarians may take account of the carrier of paper and electronic ones, consider all kinks of carriers or purchase the right of using. The traditional paper documents brings so many inconvenient in reading for users, because the readers must come to the library to find and lend the materials before gaining the resource, and sometimes they can' t find the suitable ones. And the paper documents takes more and more places. As the progress of the science and technology and the spread of the network the resources of the digital documents are more and more popular in the readers, so the rate of them in resource of the library will be higher and higher to let the readers find the resource required possible whenever and wherever in the campus network 


\section{Pay More Attention to the Collection of Grey Documents}

Grey documents is a kind of information resource of important value and not published. It concludes the conference papers, the reports of technology, the data of investigation, the experiment report, the sample of products, the catalog of products, the compile of the results of scientific study. In the university all kinds of data of experiment is easy to collect and have high value for its unique and particularity, especially the data of the experiments that failed. It mainly reports the newest trends and march of study of each field, usually has the documents of the first hand that has high potential value, academic value for collection. It is an essential information resource of construction of subject and the department of scientific study. Aimed at the profession of the construction of the key majors, librarians can take seriously of the collection, such as the scientific report, the special subject report, the record of the relevant conference, etc., especially the collection of the grey documents admittedly by the field of the library at home and abroad. These kind of documents are literature resources not gained by the usual way. Its carrier is science and technology report in house literature and the inner, the degree thesis, the conference document, the manuscript of translation, the commercial advertisement, etc. and very hard to collect. Most of the users of the documents of the key subjects in the college are the academic authority, who often attended some important academic activities. Through them, the librarians can not only know the conference information, but also gain the documents of the conference.

\section{Build the Characteristic Database and Navigation of Key Subject}

It has very important meanings to build a characteristic database, that can promote the rate of the storage and usage of the documents. First to store the characteristic document resources in electronics can deduce or avoid the abrasion and damage of the precious documents in the process of using. Second, it make it convenient to the users to retrieve and use these documents. They can gain the characteristic literature by visiting the database system through remote access to save a large amount of time and energy. Finally it is in favor of making into reality the characteristic literature databases co-construction and then share them to promote the using rate of these documents. The construction of database of the characteristic literature can build in the way of making the documents digital collected in the library, of buying the database from the data provider, or of the building the database by the librarians themselves. The range of the collection should be as complete as possible if conditioned, which includes the books, periodicals, newspapers, videos, pictures and maps, especially the resources presents the local characteristics. In the building the quality of the data and the standard of the format of the data should be paid more attention to the convenient of the co-building and sharing, which can refer to the Chinese Classification and Subject Words Table to index. Meanwhile the library should keep the communication and the contact with the collaborate libraries to make the format of the data unified and compatible. Otherwise the development and improvement of the database system should be take seriously, in brief, the database may has the friendly interface, the simply operation and have the function of accessing remotely, retrieval on line and downloading. It is the major step to supply the information for the key subjects that the characteristic database should be built. For many reasons in a long term the precious materials of key subjects is dispersed, messy, numerous and jumbled, and lack of normalized format. The researchers gained the documents and data by the way of the periodicals, the books, the papers, the patent and conference spending a lot of time and energy inefficiency.[3] The library in the college should use the method of modern technology to make the precious subject resources electronics, digitization and networking to form the database of the subject information for sharing with the characteristics of the library and as complete as possible, to make the resource an excellent resource which can be reproducible, sharing and using. The feature database may conclude the database of the bibliography of the books collected in the library, the database of the documents of the special subject, the database of the achievement of scientific study, the database of the degree papers, etc. When building the database, the librarians in the university should choose the key advantaged disciplines and build singly or jointly with the same 
software according to the data format and the standard of building of the CALIS strictly. Now the database of navigation of key disciplines have been built in the university libraries. The libraries of the college new approved can study for them to avoid the frustration and improve the work efficiency. It is necessary to emphasize that the building of the database of navigation of key disciplines is not the simple link, but is the complete introduction to the database linked, for example, the range of the discipline, the value of study, the method of retrieval and the rights of using, etc. to the level of seamless link[4].

\section{Focus on the Propaganda and Spread}

To focus on the propaganda and spread can raise the using rate of the documents resources. The rate is one of the standard to measure the value of collection and the basis of the report to the leaders superior and the fighting for the funds. The university libraries can conduct propaganda and spread the information of the feature materials collected in the library through the traditional and the new medias, such as holding the exhibition of theme documents, the classic book recommendation and the directed pushing on the platform of the homepage of the libraries of the university by e-mail, WeChat and micro blog[5], to introduce the information about the range of the books collected in the library, the collection distribution, the method of retrieval, the mode of acquisition and the construction of digital resources. Through the propaganda of full range of publicity the libraries can attract the readers and the using rate of the characteristic literature resources can increase.

\section{Take the Full Advantage of the CASHL}

CASHL is the English abbreviation of China Academic Humanities and Social Sciences Library. It is built by the Department of Education according to the development of humanities and social sciences and the demand of the construction of the documents resource. The purpose of building is to organize some university libraries having some advantaged discipline, the advantaged documents resources and the advantaged service condition to introduce some foreign periodicals of humanities and social science designed and systematically, with the help of modern service means, to make the support of the teaching and scientific study of the national college a high level of security documents. Every province has a center of the service of documents. And some of them are free to the readers of the college.

\section{Conclusion}

The development and construction of the library which is one of three pillars of the university newly approved should be put into some new thought of running a school and construct the document resources around the new location.

\section{References}

[1] The Rules of Ordinary High School Library, 2015

[2] Department of Education, 2015[14]

[3] Ping He,Discussion on development and construction a navigation,New Technology of Library and Information Service, vol.102, pp. 67-69, 2003.

[4] Li Kai, Collection development and ILL/DD services in Japanese universities, Journal of Academic Libraries, vol.5, pp. :92-98,2014.

[5] http://library.jlbtc.edu.cn 